\title{
A FORMULAÇÃO DA LITERATURA E IDENTIDADE BRASILEIRA NA CRÍTICA LITERÁRIA DE JOSÉ DE ALENCAR (1856 - 1865)
}

Alexsandro da Rosa Menez*

RESUMO: Este artigo tem como proposta analisar o desenvolvimento da ideia de identidade brasileira elaborada no campo literário. Para isso, dirigimos nosso exame ao escritor José de Alencar, demonstrando sua importante contribuição para a concretização da nacionalidade brasileira que vinha sendo gestada desde os primeiros escritores românticos, como os literatos em torno da revista Nitheroy, lançada em Paris no ano de 1836.

PALAVRAS-CHAVE: Literatura e História; José de Alencar; Identidade Brasileira; Nacionalismo.

\section{The formulation of Brazilian literature and indentity in José de Alencar's literary criticism (1856 - 1867)}

ABSTRACT: This article aims to analyze the development of Brazilian identity idea elaborated in the literary field. For this, we drove our examination to writer José de Alencar demonstrating his important contribution to the achievement of Brazilian nationality that had been gestating since the early romantic writers, as writers around the Nitheroy magazine, launched in Paris in 1836.

KEYWORDS: Literature and History; José de Alencar; Brazilian Identity; Nationalism.

\section{La formulación de la literatura y identidad brasileña em la crítica literaria de José de Alencar (1856 - 1865)}

RESUMEN: Este artículo tiene como objetivo analizar el desarrollo de la idea de la identidad brasileña trabaja en el campo literario . Para ello, nos dirigimos nuestro examen al escritor José de Alencar demostrando su importante contribución a la consecución de nacionalidad brasileña que había sido gestando desde principios de los escritores románticos, como escritores de todo el Nitheroy revista, lanzada en París en 1836.

PALABRAS-CLAVE: Literatura y Historia; José de Alencar; Identidad Brasileña; Nationalismo.

\footnotetext{
* Mestre em História pela Pontifícia Universidade Católica do Rio Grande do Sul (PUC-RS). Mestrando em letras pela Universidade Federal de Santa Maria (UFSM). E-mail: alex.r.menez@gmail.com
} 


\section{Introdução}

Discutir sobre questões que envolvem as noções de nação e identidade nacional e os seus respectivos movimentos nacionalistas é uma proeza um tanto complicada de se realizar. Sua bibliografia é tão vasta que até mesmo seus dois primeiros estudiosos, o francês Ernest Renan e o inglês Lord Acton, funcionam, ao mesmo tempo, como autores referenciais e objetos de estudos. São referências através dos textos Que es una nacion (2000), do primeiro - que consiste em uma conferência proferida na Sobornne, de Paris, em 1882 - e o artigo "Nacionalidade" (2000), do segundo, publicado em 1862 na revista The Home and Foreign Review. E objetos de estudos por parte de estudiosos mais contemporâneos, por exemplo, como o inglês Anthony D. Smith que analisou os pressupostos ideológicos do pensamento de Lord Acton, elaborado no século XIX - no que se refere às ideias de nação e nacionalismos (2000, p. 190) -, e o argentino Elías Palti (2006) que fez o mesmo tipo de análise com Ernest Renan. A diferença entre os estudos de ambos se encontra no fato de que o primeiro se preocupa mais com os elementos do contexto histórico/social que condicionaram o pensamento de Acton e, por sua vez, o segundo se interessa pelo contexto histórico/linguístico de Renan.

Isso que esboçamos acima exemplifica a dificuldade de se lidar com esse tipo de temática, na qual o mecanismo de referência pode ser também um elemento de análise. Esse tipo de característica só comprova que o campo dos estudos históricos pode ser de excelente ajuda para o entendimento dos fenômenos nacionais, pois induvidosamente eles são - inclusive seus estudiosos - passíveis de historicidade. Tendo clarificado essa questão, partiremos para outro ponto mais restrito ao cenário americano que torna o estudo desse fenômeno tão problemático.

Segundo expõe o estadunidense Don H. Doyle e o brasileiro Marco Antonio Pamplona (2008, p. 17), na introdução “Americanizando a conversa sobre o nacionalismo", do livro - organizado por eles - Nacionalismo no Novo Mundo (2008), tanto a produção como o interesse no surgimento dos movimentos nacionais na América têm sido negligenciados pelo debate internacional dessa temática. Em razão desse último, eles comentam que a experiência gerada por esses estudos poderia contribuir para uma melhor compreensão dos fenômenos nacionais ao afirmarem que "os americanistas não estão deixando de lado o debate sobre o nacionalismo; mas é esse debate que está deixando de lado as Américas" (2008, p. 18). ${ }^{1}$ Esse descaso das pesquisas em torno das nacionalidades 
produzidas na América tem por base o pressuposto de que esse continente não se enquadra dentro do paradigma europeu de nação. Para ilustrar essa hipótese, os autores citam Walker Conner - um importante estudioso europeu do nacionalismo -, que fez a afirmação de que o povo americano não constitui uma nação no sentido original da palavra, porque não possui uma língua própria (1995, p.55-46).

Levando essa perspectiva europeia em consideração, não podemos negar que apesar dos diversos estudos sobre a formação da nacionalidade americana, restringindo especificamente o nosso olhar ao caso brasileiro - essa peculiar diferença com a Europa, geralmente, não é levada em conta quando abordamos a formação da nossa identidade nacional. Isso ocorre porque as teorias que versão sobre a formação das nações modernas de matriz europeia - são comumente utilizadas como modelos explicativos de uma realidade empírica, para a qual elas não foram elaboradas. Utilizamos as teorias como modelos e conceitos prontos para explicar um fenômeno histórico e não para compreender as circunstâncias que lhe deram origem. Um exemplo disso, é a utilização dos conceitos como a "invenção da tradição", de Eric Hobsbawm (1990), ou "comunidade imaginada", de Benedict Anderson (2008), para explicar os fenômenos nacionais e identitários do Brasil. Ambos estão presentes em quase todas as pesquisas brasileiras que envolvem as noções anteriormente mencionadas. Não refutamos o seu uso, pelo contrário, acreditamos que eles são trabalhos essenciais para o entendimento do complexo fenômeno das nacionalidades. Contudo, essa área de pesquisa necessita de uma maior diversificação bibliográfica, assim como a teoria nacionalista deveria ser usada como um instrumento reflexivo e não apenas como uma "bengala teórica", como comumente vem sendo utilizado.

Tendo isso por base, objetivamos com este artigo demonstrar que a formação da identidade e nação brasileira, durante o século XIX, ocorreu conjuntamente com a formação da literatura nacional, tendo como figura guia o escritor José de Alencar. Mas nossa contribuição, um pouco diferente dos diversos trabalhos que tratam da literatura alencariana, é mostrar o impulso dado por esse autor, seguindo o caminho traçado pelos literatos em torno da revista Nitheroy, através de sua crítica literária - ou podemos denominar "crítica literária futura" - funcionando como um modelo para a literatura brasileira que deveria ser produzida. Aliás, isso é uma das tantas especificidades que demonstram a peculiaridade da construção da nação brasileira e, por conseguinte, a inevitabilidade de um maior cuidado nas futuras abordagens sobre esse assunto. 


\section{Parte I}

Não nos é estranha a afirmação de que o século XIX foi um período caracterizado pela efervescências das nacionalidades, a partir do surgimento dos modernos estados nacionais. Nesse contexto, a história, como disciplina especializada do saber humano, se tornou extremamente importante para validar a existência desses nascentes Estados nacionais. O Brasil, assim como todo continente americano, não ficou a margem dessa onda nacionalista que iniciou no Velho Mundo. ${ }^{2}$ Contudo, como já salientamos, a formação de sua nacionalidade ocorreu com algumas peculiaridades em relação ao continente europeu.

Em primeiro lugar, o território onde hoje existe a nação brasileira era, ainda no início do século XIX, apenas uma possessão ultramarina do Império Português. Contudo, apesar de ter se emancipado politicamente em $1822^{3}$, a independência cultural do Brasil, ou melhor, a construção de sua originalidade em relação a Portugal ocorreu posteriormente a essa data. ${ }^{4}$ Nesse sentido, é possível afirmar que os agora brasileiros, e não mais portugueses na América, somente gozaram de sua autonomia algumas décadas depois da ruptura política. Para os estudiosos da literatura, esse processo da formulação de uma entidade cultural à parte da portuguesa somente teve início em 1836, com a publicação, em Paris, da revista Nitheroy. ${ }^{5}$ Por outro lado, os historiadores, na defesa de seu campo, advogam que o início desse processo ocorreu com a constituição do IHGB (Instituto Histórico e Geográfico Brasileiro), em 1838, cujas bases para uma história nacional surgiu a partir do texto, do naturalista Carl von Martius, Como se deve escrever a história do Brasil $^{6}$, publicado na revista do $\mathrm{IHGB}^{7}$, em 1844. Além disso, segundo Manoel Luis Salgado Guimarães (1988) e Temístocles César (2003), Vanhargen, com sua obra História Geral do Brasil, publicada entre 1853 1854, teria colocado em prática as sugestões do naturalista europeu.

Em segundo lugar, o movimento nacionalista brasileiro foi desencadeado, ou influenciado, por sugestões estrangeiras. Uma proposta, dentro do arcabouço do pensamento romântico do entrecruzamento racial - identificado como noção mais próxima das características culturais de um grupo social - coloca esse entrecruzamento como elemento fundamental da identidade brasileira. Tal ideia aparece tanto no Resumo da história literária do Brasil publicado por Ferdinand Denis ${ }^{8}$, em 1826, quanto no já citado texto de Carl Von Martius. A influencia estrangeira é uma questão muito peculiar no desenvolvimento da nacionalidade brasileira, todavia, para se afirmar, seguindo os 
paradigmas românticos, também europeus em sua origem, necessitava de uma literatura que lhe fosse própria, ou seja, uma literatura brasileira.

\section{Parte II}

A primeira menção à existência de uma literatura brasileira foi feita pelo erudito alemão Friedrich Bouterwek (1765-1828), em uma obra coletiva que versava sobre a arte e a ciência desde o Renascimento até o fim do século XVII. ${ }^{9}$ Conforme Guilhermino Cesar, aquele autor ocupou-se da literatura portuguesa com o livro Geschichte der Portugiesischen Poesie und Beredsamkeit (História da Poesia e da Eloquência Portuguesa), publicado no ano de 1805 (1978, p.XV). Nesse livro, Bouterwek menciona dois escritores nascidos no Brasil, Antônio José, o Judeu (1978, p.32-36) e Cláudio Manoel da Costa (1978, p.37-40). Para o erudito alemão, apesar de falar no início do século XIX, não haveria ainda nenhuma separação entre a literatura portuguesa e brasileira.

Foi somente em 1826 que o já citado francês Ferdinand Denis (1798-1890), elaborou a primeira interpretação da literatura brasileira como estando à parte da portuguesa. Ele foi o primeiro a propor alguns elementos que poderiam ser usados na constituição de uma literatura própria brasileira separada da portuguesa em seu texto Résume de l'Histoire Littéraire du Portugal, suivi du Résumé de l'Histoire Littéraire du Brésil $^{10}$.

Na parte em que menciona o Brasil, o estudioso francês demonstrou que os impérios ibéricos, em particular Portugal, proibiam as suas colônias de desenvolver letras próprias, ocasionando o relativo atraso na cultura local. Para ele, apesar da chegada da corte portuguesa, em 1808, no solo americano - ou mesmo com a constituição de um império independente -, os intelectuais brasileiros ainda tomavam de empréstimo a literatura portuguesa. Ele afirmava que para o Brasil constituir sua originalidade, era necessário que a formação de uma literatura diferente da portuguesa. Por conseguinte, Denis sugeriu que essa diferenciação poderia ser concretizada através do uso de modelos e temáticas distintos dos utilizados pelos europeus. Nesse sentido, os escritores brasileiros deveriam parar de utilizar o estilo clássico, pois afirmava que ele não era compatível com o clima e a natureza americana.

A América, favorecida pela natureza, deveria procurar ter um pensamento próprio, diga-se original, que a particularizasse das demais nações. Diante de tudo isso, Denis 
propôs que os brasileiros buscassem nos primitivos americanos as bases para a constituição de sua originalidade (1978, p.35-37). Conforme ele salienta, "estudados que sejam os leves vestígios remanescentes de três séculos de destruição, aí se acharão todos os pensamentos primitivos que excitam fortemente a imaginação" (1978, p.37).

Ainda em 1826, o português Almeida Garrett (1998) sugeriu que os brasileiros deveriam aproveitar mais a sua natureza local e, semelhantemente a Denis, abandonar o estilo clássico europeu. Segundo ele:

Certo é que as majestosas e novas cenas da natureza naquela vasta região deviam ter dado a seus poetas mais originalidade, mais diferentes imagens, expressões e estilo, do que neles aparece: a educação europeia apagou-lhes o espírito nacional: parece que receiam de se mostrar americanos; e daí lhes vem uma afetação e impropriedade que dá quebra em suas melhores qualidades (1998, p.56-57).

Essa questão da falta de originalidade mencionada por Garrett, e também salientada por Denis, é um princípio básico do pensamento romântico. Conforme Afrânio Coutinho, essa corrente de pensamento se constitui como um movimento internacional sendo um estilo artístico, individual e de época comum aos escritores do período (1968, p.139). Temos que levar em consideração, que o Romantismo foi uma corrente revolucionário de pensamento, elaborada em oposição à tradição neoclássica existente no século XVIII, cuja inspiração - ao contrário do Classicismo que tinha por básica a antiguidade - vinha do período medieval (1968, p.140). Segundo o mesmo Coutinho:

As novas tendências que se opuseram no meado do século XVIII aos ideais neoclássicos, preludiando o Romantismo, refletem um estado de espírito inconformista em relação ao intelectualismo, ao absolutismo, ao convencionalismo clássicos, ao esgotamento das formas e temas então dominantes. A imaginação e o sentimento, a emoção e a sensibilidade, conquistam aos poucos o lugar que era ocupado pela razão. A noção de natureza e seus corolários - a bondade natural, a pureza da vida em natureza, a superioridade da inspiração natural, primitiva, popular, - atraem cada vez mais o interesse e o pensamento dos homens (1968, p.141).

Conforme esboçado pelo estudioso brasileiro, a exigência dos preceitos românticos por parte dos europeus, significava naquele período à adoção do que se tinha de mais moderno no tocante ao pensamento filosófico sobre o mundo. Sendo assim, se observarmos a diferença entre o Classicismo - ou Neoclassicismo adotado pelos europeus - e o Romantismo, no qual o primeiro tem por base o "primado da razão, do decôro, da contenção", o romântico vai ao extremo oposto sendo "exaltado, entusiasta, colorido, emocional e apaixonado", escapando do mundo real para o mundo do passado, procurando 
assim "idealizar a realidade, e não reproduzi-la" (COUTINHO, 1968, p.143). Chegaremos à conclusão de que o caminho para a constituição de uma nacionalidade brasileira a parte da portuguesa, finalizando assim o caminho empreendido pela via política, somente teria êxito com a adoção dos princípios românticos. Caminho esse que seria concretizado principalmente através da literatura e, diferentemente do caso europeu, pouco alcançado com a história. Assim, como tentaremos demonstrar, seu impulso inicial se deu através da crítica de uma literatura que mal existia.

Segundo Antonio Candido, no caso brasileiro, no tocante à literatura, as formas e temas tradicionais já estavam demonstrando suas insuficiências para exprimir os modernos pontos de vista sobre a realidade. Por isso, é possível dizer que o Romantismo no Brasil "foi uma fratura salutar que permitiu sensível desafogo devido à substituição ou, quando menos, reajuste dos instrumentos velhos, com evidentes benefícios da expressão". Através disso, houve compensação dos prejuízos, "uma vez que seria impossível guardar as vantagens do universalismo e do equilíbrio clássico, sem asfixiar ao mesmo tempo a manifestação do espírito novo na pátria nova". Como afirma o crítico literário, "graças ao Romantismo, a nossa literatura pôde se adequar ao presente" (1975, p. 9).

Para Candido, a partir da independência se desenvolveu a intuição patriótica de dotar o Brasil com uma literatura equivalente à europeia através do romance e teatro. Esse movimento acabou se ligando, por cima de uma fatura expressional, ao período árcade da literatura brasileira, pois havia o desejo de se criar uma literatura nacional, como se dizia na época (1975, p.9-10). O ponto crucial passou a ser a elaboração de algo que demonstrasse a identidade brasileira, mesmo sem ainda saber como. No caso, comenta Candido, que a matéria, para ser nacional, e esse é o ponto, deveria ser obtida através da harmonização das tradições indígenas com as portuguesas. Esse engajamento foi o senso de dever patriótico que se manteve ao longo de todo o Romantismo brasileiro, no qual "levava os escritores não apenas a cantar a sua terra, mas a considerar as suas obras como contribuição ao progresso" (1975, p.10).

\section{Parte III}

Até aqui ficou claro que somente foi possível falar em uma literatura nova no Brasil, quando se adquiriu consciência da possibilidade de transformá-la, visando promovê-la de forma intencional. Em razão disso, portanto, foi somente entre 1833 e 1836 
que um grupo de jovens em Paris obteve essa proeza, sendo eles Domingos José Gonçalves de Magalhães, Manuel de Araújo Porto Alegre, Francisco de Sales Torres Homem, João Manuel Pereira da Silva, Cândido de Azeredo Coutinho, sob a liderança do primeiro. Para Afrânio Coutinho, esse grupo foi capaz de fundir em torno do projeto de criação da nação brasileira, os campos da literatura e da política, fazendo com que ambas as áreas trabalhassem a favor da autonomia cultural do Brasil. Pode-se dizer que "sua atitude intencionalmente revolucionária, de renovação total da literatura brasileira, expressa no manifesto lançado pela revista Niterói " (1968, p.159-160), ficou caracterizada pelo seu antilusitanismo, demonstrado nas suas disposições em transferir para a França, nesse caso Paris, o lugar de inspiração para os brasileiros. Aliás, como salienta Coutinho, foi nesse território que aquela revista foi publicada.

Salientando a influência estrangeira entre os brasileiros desse grupo, Candido menciona que eles aceitaram a sugestão de Denis e de Garrett, passando a utilizar o índio como modelo literário. Com isso, instituíram o objeto tão necessária à nascente nação para uma literatura própria, com uma tradição literária de temática indianista, que teria iniciado com o Caramuru, de Basílio da Gama, e o Uraguai, de Santa Rita Durão (1975, p.12). Ainda segundo o mesmo autor, entre aqueles primeiros românticos:

\begin{abstract}
Exprime-se, de modo vago e implícito, a idéia (acentuada por Denis apenas na parte relativa ao indianismo) de que alguns brasileiros, como Durão, Basílio, Sousa Caldas, José Bonifácio, haviam mostrado o caminho a seguir, quanto a sentimentos e temas. Bastava prosseguir no seu esforço, optando sistematicamente pelos assuntos locais, o patriotismo, o sentimento religioso (CANDIDO, 1975, p.12-13).
\end{abstract}

Candido resume tudo isso ao dizer que "estava lançada a cartada, fundindo medíocre, mas fecundamente, para uso nosso, o complexo Schlegel-Stäel-HumboldtChateaubriand-Denis" $(1975,13)$.

Por outro lado, e essa é a nossa questão principal, esse passo decisivo empreendido pelos brasileiros, através da criação da revista Niterói, não ocorreu pelo meio literário, mas por meio de estudos críticos - ou sendo mais específico, uma história - de uma literatura ainda escassa. Dessa forma, foram os trabalhos críticos de Pereira da Silva e Gonçalves de Magalhães que serviram de ponto de partida para a teoria do nacionalismo literário e político brasileiro.

Foi através do texto, intitulado Ensaio sobre a história da literatura no Brasil (1999), que Magalhães esboçou as primeiras noções do conceito de literatura que seria 
empregada pela nascente nação brasileira. Para ele:

A literatura de um povo é o desenvolvimento do que ele tem de mais sublime nas idéias, de mais filosófico no pensamento, de mais heroico na moral, e de mais belo na natureza, é o quadro animado de suas virtudes, e de suas paixões, o despertador de sua glória, e o reflexo progressivo de sua inteligência (1999: 29).

A literatura é o caráter de um povo, seu espírito, que consegue vencer o tempo e, por isso, chega aos herdeiros dos que já não existem mais. Portanto, a literatura é a herança espiritual dos nossos antepassados, seu legado, seu íntimo e sua alma (MAGALHÃES, 1999, p.29). O que percebemos a partir desses trechos é a literatura compreendida não como uma arte, mas como expressão da nacionalidade de um povo. Isso fica ainda mais patente na citação seguinte de Magalhães, ao dizer que:

[...] quando esse povo, ou essa geração desaparece da superfície da Terra com todas as suas instituições, suas crenças, e costumes, a literatura só escapa aos rigores do tempo, para anunciar às gerações futuras qual fora o caráter do povo, do qual é ela o único representante na posteridade.

[...] sua voz como um eco imortal repercute por toda a repercute por toda a parte, e diz: em tal época, debaixo de tal constelação, e sobre tal ponto da Terra um povo existia, cujo nome eu só conservo, cujos heróis eu só conheço; vós porém se pretendeis também conhecê-lo, consultai-me, porque eu sou o espírito desse povo, e uma sombra viva do que ele foi (MAGALHÃES, 1999, p.29).

Além da instauração de uma tradição literária, que dê voz à nacionalidade brasileira como defendia Magalhães, temos aí também o surgimento de uma outra tradição da literatura brasileira pela sua intrínseca relação com a sociedade. Aliás, ao longo de seu desenvolvimento isso será cada vez mais latente. Podemos, por exemplo, apenas mencionar de passagem o ponto alto dessa relação na produção literária como ocorrendo a partir da década de 30, do século XX que será conhecido como "Romance de 30". Mas, retornando a essa outra geração de 30, a do século XIX, chegamos a mesma afirmação de Bernardo Ricupero, de que nesse período todo o continente latino-americano - após as lutas pela emancipação política das antigas metrópoles -, procurou encaminhar os primeiras passos para a construção cultural (2004: XIX).

\section{Parte IV}

Apesar desse ato inaugural na tentativa de formular as bases para a ideia da nacionalidade literária brasileira, de fato foi somente a polêmica em torno do livro de 
Magalhães, Confederação dos Tamoios, durante o ano de 1856 - em que participaram José de Alencar, Araújo Porto Alegre, Monte Alverne e, até mesmo, o próprio imperador D. Pedro II - que se constitui uma forte base conceitual para a formulação da ideia de nação e identidade brasileira.

Os artigos em torno dessa polêmica foram publicados no jornal Diário do Rio de Janeiro, durante o ano de 1856. Posteriormente, no mesmo ano, Alencar reuniu essas cartas e as publicou em livro sob o nome de Cartas da Confederação dos Tamoios, impresso na tipografia daquele mesmo jornal.

Segundo José Aderaldo Castello, a obra de Magalhães, Confederação dos Tamoios, foi publicada no ano de 1856, em uma luxuosa edição imperial, patrocinada pelo próprio imperador D. Pedro II. Conforme comenta esse autor, Magalhães cometeu o equívoco de retomar uma forma literária anacrônica, a epopeia (1999, p.260). Isso pesou muito nas críticas proferidas por Alencar sobre aquele protegido do monarca brasileiro. Para Castello, mesmo Alencar tendo percebido os malefícios do mecenato sob aquele escritor, ele preferiu não se deter nesse. Suas principais intenções, segundo as palavras do estudioso foram as de "alimentar a consciência crítica interna" da obra, sem elogios ou críticas pessoais (1999, p.260-261). Por fim, Castello destaca que essa é "a primeira e mais importante polêmica do nosso Romantismo, de significado relevante e indispensável ao estudo do indianismo como ideologia e poética romântica" (1999, p.261).

As cartas escritas por Alencar e endereçadas ao jornal supracitado, foram assinas sob o pseudônimo de Ig. No livro publicado no mesmo ano da polêmica, ele explica em tom sarcástico o significado do nome utilizado durante toda polêmica:

O pseudonimo de Ig. foi tirado das primeiras lettras do nome Iguassú, heroina do poema; ninguem dirá pois que a Confederação dos Tamoyos não é capaz de inspirar, quando suscitou-me a idéa de um pseudônimo que fez quebrar a cabeça de muita gente (ALENCAR, 1953, p.4). ${ }^{11}$

Em seguida, ele explica que os seus textos não tiveram colaboradores e, por isso, não fora induzido a escrever tais críticas. Para realizá-las, no entanto, necessitou da ajuda dos "mestres como Chateaubriand e Lamartine de quem lia algumas páginas para ter a coragem de criticar um poeta de reputação como é o Sr. Magalhães" (1953, p.4). O futuro escritor de Iracema foi bastante duro com a obra de Magalhães, mesmo que tenha iniciado seu texto se isentando da postura de crítico literário e se colocado mais como apenas um leitor, ao dizer que "são apenas as impressões de minha leitura, que desejo communicar- 
lhe, para que as publique se entender que o merecem, e que são justas”. Logo em seguida, ele comenta asperamente que o assunto do poema, retirado do período colonial brasileiro, é interessante "dava thema para uma divina epopéia, se fosse escripto por Dante" (1953, p.4).

Mais adiante, comenta que a primeira parte do poema é fria devido à forma como Magalhães invocou o sol e os gênios do Brasil. Para ele, o sol brasileiro, "esse astro cheio de esplendor e de luz, devia inspirar versos mais repassados de enthusiasmo e de poesia". Questionando o uso da natureza brasileira, Alencar diz que Virgílio, Chateaubriand, Camões e Byron, que escreveram muito bem sobre suas pátrias, "terião achado no sol do Brasil algum novo raio, alguma centelha divina para illuminar essa tela brilhante de uma natureza virgem e tão cheia de vida" (1953, p.5). Contudo, o escritor de Suspiros poéticos e Saudades, não chegou nem perto do que teriam feito aqueles mestres das letras.

Para Alencar, a segunda parte da obra tem "certa beleza", todavia, com algumas ressalvas, pois nela Magalhães conseguiu descrever mais adequadamente o Brasil. Segundo ele, "ha n'essa descripção muitas bellezas de pensamento, mas a poesia, tenho medo de dizê-lo, não está na altura do assumpto". Saindo do campo crítico e entrando no de futuro escritor, Alencar comenta que, se algum dia fosse poeta, "se quizesse compor um poema nacional, pediria a Deus que me fizesse esquecer por um momento as minhas idéas de homem civilisado", para, somente dessa forma, conseguir se integrar à natureza e dela obter inspiração. Caso não conseguisse isso, "quebraria a minha Penna com desespero". Entretanto, jamais "mancharia n'uma poesia menos digna de meu bello e nobre paiz" $(1953$, p.5).

Esses apontamentos permitem a Alencar questionar algo que é inexplicável para ele: como o Brasil pode ser tão esplendoroso e não conseguir inspirar os seus filhos. Indagando-se sobre o motivo de nenhum poeta conseguir cantar sua pátria brasileira, ele chega à obscura previsão de que é necessário fazer isso o quanto antes, porque "civilisação ahi vem: o wagon do progresso fumega e vai precipitar-se sobre essa têa immensa de trilhos de ferro que em pouco cortarão as tuas florestas virgens", no qual "os turbilhões de fumaça e de vapor começarão a ennovelar-se, e breve obscurecerão a limpidez d'essa atmosphera diaphana e pura" (1953, p.5-6). Por esse motivo, ele afirma que é melhor gravar poeticamente o quanto antes as belezas desta terra antes que as mesmas desapareçam. E, em um tom essencialmente nacionalista, Alencar complementa esses comentários dizendo que: 
Quem sabe! Talvez isto seja necessário. O Brasil, em toda a sua belleza natural, offusca o pensamento do homem como a luz forte, que deslumbra a vista e cega; é preciso que essa luz perca um pouco de sua intensidade para que olhos humanos possão se habituar a ella $(1953$, p.6).

Terminada essa divagação em torno da natureza brasileira, ele retoma o fio crítico da obra de Magalhães fazendo a seguinte exclamação: "Ia-me esquecendo o poema: é natural! A descripção do Brazil inspira-me mais enthusiasmo do que o Brasil da descripção". Segundo Alencar, o Amazonas não é bem descrito e faltou a descrição do rio Paraná. A pintura dos índios não tem beleza, pois há uma grande gama de conteúdo que não foram utilizados por Magalhães. No entanto, o mais agravante é a falta de majestade e elevação dos heróis de seu poema. A respeito disso, ele comenta que em todas as epopeias conhecidas por esse crítico, é dada "uma origem divina, ou ao menos heroica, ao povo que pretendem cantar" (1953, p.6). Esse preceito formal foi realizado por Homero, Virgílio e Camões. Por conseguinte, ele indica que "um poema epico, como eu comprehendo, e como tenho visto realizado, deve abrir-se por um quadro majestoso, por uma scena digna do elevado assumpto que se vai tratar" (1953, p.7).

Esses parâmetro teóricos da epopeia não foram seguidos pelo autor de $A$ Confederação dos Tamoios. O começo do poema é fraco, porque mostra apenas "a morte de um simples guerreiro índio". Alencar considera isso um profundo erro estético desse gênero literário. Consequentemente, isso faz com que a parte inicial seja fraca, "a causa do poema, o principio da acção não está de modo algum nas regras da epopéia”. Segundo esses padrões, é nessa parte inicial que se encontra a "ação causal" que funcionará como o motor da história. Nesse sentido, Magalhães não seguiu o modelo dos autores clássicos, segundo salienta o crítico "ha pois n'estes poemas como causa, ou um grande infortunio, ou um sentimento poderoso como a nacionalidade e a religião, ou um acontecimento importante como a descoberta de um novo mundo", sendo a causa de Magalhães "um facto bem comum", uma simples vingança. Ela não consegue transformar o poema em uma grande epopeia. Por isso, na opinião de Alencar, Magalhães deveria tê-lo iniciado no conselho dos chefes tamoios, que está presente no segundo canto da obra (1953, p.7).

No tocante à metrificação, na percepção mordaz de Alencar, o poeta de Suspiros poéticos foi inteiramente descuidado. Segundo ele, isso teria sido algo natural, "pois o estudo da poesia estrangeira provavelmente fez-lhe perder o gosto apurado e a suavidade e cadencia do verso portuguez" $(1953$, p.8).

$\mathrm{Na}$ segunda carta, Alencar critica o fato de os índios tamoios não terem se 
confederado por um nobre motivo, mas "unicamente para acabar com os ataques reiterados dos Lusos" (1953, p.11). Além disso, indicando novamente os erros formais de Magalhães, ele diz como deve ser a poesia épica:

\begin{abstract}
Para mim um poeta, e sobretudo um poeta épico, deve ser ao mesmo tempo autor e actor: como autor elle prepara a scena, ordena a sua decoração, e tira todo o partido da ilusão teatral; como actor é obrigado a dar a todas as suas palavras, ao seu estylo, um tom e uma elevação que esteja na altura do pensamento (1953, p.11).
\end{abstract}

Como é possível percebermos no entendimento futuro autor de O gaúcho, Magalhães foi incapaz de seguir esse movimento simples da epopeia. Sendo assim, para Alencar, o autor dessa "falsa" epopeia estaria distante até mesmo do seu pretenso antecessor Basílio da Gama. Faz tal insinuação ao comentar mordazmente que "não creia, meu amigo, que pretendo dar ao Uruguay os foros de um modelo de poesia brasileira; não: nem J. Basilio era um verdadeiro poeta nacional, embora nascido no Brazil, nem escreveu uma epopéia, mas um simples poemeto, um pequeno espisodio" (1953, p.14). Apesar disso, diferente do autor de A Confederação dos Tamoios, o autor de Uraguai "teve alguns raios de inspiração, alguns bafejos das auras da nossa terra, como ainda não encontrei na Confederação dos Tamoyos" (1953, p.14-15).

Nos últimos trechos da segunda carta, Alencar comenta que: "escreveriamos um poema, mas não um poema épico; um verdadeiro poema nacional, onde tudo fosse novo, desde o pensamento até a fórma, desde a imagem até o verso". Percebemos nesse trecho a sua incredulidade para a capacidade da poesia épica funcionar como representação da nacionalidade brasileira. Segundo ele, "a fórma com que Homero cantou os Gregos não serve para cantar os indios" (1953, p.17). A forma que seria mais adequada para realizar esse empreendimento seria o romance em prosa. Aliás, sugestão essa que seria concretizada pelo próprio Alencar, no ano seguinte do surgimento das cartas, com a publicação do romance $O$ Guarani (1857).

Outro erro de Magalhães foi a pouca exploração da personagem feminina, algo que talvez seja indicado desde o início pelo crítico Alencar ao escolher como pseudônimo as duas primeiras letras da heroína Iguassu. Conforme ele comenta, "o Sr. Magalhães, escrevendo um poema nacional, estava obrigado a formar de sua heroína uma mulher que pudesse figurar a par d'essas imagens graciosas que a literatura conserva, desde a Venus de Milo e a Helena dos Gregos, até a Fornarina de Raphael e a Arminda do Tasso" (1953, 
p.19). No entanto, “a heroína do poema do Sr. Magalhães, é uma mulher como qualquer outra" (1953, p.20). E, ainda retomando a tema indianista, ele compara Magalhães a outro nacionalista brasileiro: o "Sr. Gonçalves Dias, nos seus cantos nacionaes, mostrou quanta poesia havia n'esses costumes índios, que nós ainda não parecíamos bem, porque os vemos de muito perto". Ele explica que isso se deve ao fato da poesia ser semelhante à pintura, pois, para vermos melhor, é necessário haver certa distância para com o objeto pintado. Há também, em suas obras antes da confederação, uma nênia americana que é um "verdadeiro typo da poesia nacional; há ahi o encanto da originalidade" (1953, p.20). Mas Alencar salienta que até esse ponto da poema A Confederação dos Tamoios, ainda não conseguiu ver essas coisas, pois, segundo ele, a "heroína do poema é, como já lhe disse, uma mulher que se chama Iguassú, e nada mais" (1953, p.21).

$\mathrm{Na}$ quarta carta, Alencar afirma que o poeta não conseguiu retratar o belo, "porque deixou de engrandecer o seu assumpto e a historia nacional". O poema ficou restrito apenas a luta entre os indígenas e os portugueses. Para o crítico, o belo que vem sendo usado na literatura nacional é algo que não denota naturalidade, pois transmite apenas uma noção de plasticidade (1953, p. 26). A isso, soma-se o fato de que:

De ha algum tempo se tem manifestado uma certa tendencia de reacção contra essa poesia inchada de termos indígenas, essa escola que pensa que a nacionalidade da litteratura está em algumas palavras: a reacção é justa, eu também a partilho, porque entendo que essa escola faz grande mal ao desenvolvimento do nosso bom gosto litterario e artistico (1953: 27).

Alencar pondera para que esse tipo de reação não se exceda em suas críticas, já que “em vez de condenar o abuso, combata a cousa em si". Em outras palavras, "em lugar de stygmatisar alguns poetastros que perdem o seu tempo a estudar o diccionario indigena, procure lançar o ridículo e a zombaria sobre a verdadeira poesia nacional”. Ele considera um erro daqueles brasileiros que defendem "que as nossas raças primitivas erão raças decahidas, que não tinham poesia nem tradicções" e ainda "concluem d'aqui que devemos vêr a natureza do Brasil com os olhos do europeu, exprimil-a com a phrase do homem civilisado, e sentil-a como o individuo que vive no doce confortavel" (1953, p. 27). Por esse uso considerado equivocado do indígena, ele lamenta dizendo que:

Eis, meu amigo, um paradoxo em litteratura um sophisma com que nos procuramos illudir por não termos tido ainda um poeta nacional. Eu dejsejava que Child-Harold, na sua peregrinação, tivesse sido arrojado pela tempestade n'uma praia do Brasil, e que, em vez de Haydéa, tivesse encontrado Lindoia ou Moema: desejava ardentemente isto, para dar um desmentido áquelles que entendem que a 
nossa natureza não é bastante rica para crear ella só uma epopéia (ALENCAR 1953, p.27).

Para Alencar é possível fazer poesia até mesmo sobre uma coisa vulgar, como mostraram Chateaubriand, Virgilio e Eugène Pelletan (1953, p.27). Segundo ele, "Buffon na sua historia natural é um poeta que faz um pequeno poema sobre cada animal, cada ser da creação", há poesia em qualquer coisa viva, "em tudo pois ha poesia, comtanto que se saiba vibrar as cordas do coração, e fazer scintillar esse raio de luz que Deus deixou impresso em todas as cousas, como o cunho de seu poder creador" (1953, p.28). Contudo, existe aqueles maus poetas que:

[...] até hoje têm explorado a litteratura nacional, em vez de procurar o bello nas cousas, julgão que o achão em duas ou, tres palavras indígenas, em uma meia dúzia de costumes selvagens; e atirão aos leitores essa palavras e esse costume, deixando a cada um a liberdade de ir procurar na sua imaginação a poesia que oculta esse mytho indecifrado da litteratura patria (ALENCAR, 1953, p.28).

Como podemos perceber nessa última citação, Alencar não considera que a nacionalidade da literatura brasileira esteja caracterizada apenas pelo uso do índio ou de algumas palavras de qualquer grupo ameríndio. Ele defende que é necessário realizar o mesmo que Santa Rita Durão fez em o Caramuru, uma poesia na qual, diferente da obra de Magalhães, pode ser encontrada elementos mais substanciais sobre os antepassados nacionais. Contudo, comenta Alencar, "o que porém nunca perdoarei ao Sr. Magalhães é o ter deixado passar pelo seu poema, como uma sombra vaga e esvanecida, aquelle vulto magestoso de José de Anchieta, aquelle apostolo digno de ser cantado por Homero (1953, p.29).

Na quinta e última carta, Alencar é categórico ao afirmar que Magalhães não é um poeta, pois usa da linguagem sem arte, despreza as belezas do estilo e apresenta milhares de versos sem harmonia, em seu poema ele "não escreveu versos; alinhou palavras, mediu syllabas, accentuou a lingua portugueza á sua maneira, creou uma infinidade de sons cacophonicos, e desfigurou de um modo incrivel a sonora e doce filha dos Romanos poetisada pelos Arabes e pelos Godos” (1953, p.34). O problema para Alencar não é somente o fato de Magalhães ter fracassado em sua tentativa de criar uma epopeia nacional, mas - algo anteriormente destacado no início de sua crítica a obra A Confederação dos Tamoios - o gênero literário que foi escolhido para retratar a nacionalidade brasileira (1953, p. 40). Não era apenas a utilização incorreta da temática indianista que Alencar 
alegava insuficiente para a representação da nacionalidade brasileira, era também a incompatibilidade da epopeia como encarnação da identidade nacional. Ele reitera essa afirmação ao dizer que:

Estou bem persuadido que se Walter Scott traduzisse esses versos portuguezes no seu estylo elegante e correcto; se fizesse d'esse poema um romance, dar-lhe-ia um encanto e um interesse que obrigarião o leitor que folheasse as primeiras paginas do livro a lêl-o com prazer e curiosidade (1953, p.40).

Todas essas questões apresentadas na crítica literária de Alencar a obra de Magalhães são demonstrativos do que nos referimos antes, o longo caminho traçado pela crítica e historiografia literária - desde os textos daqueles literatos europeus, passando por Magalhães e o grupo da Nitheroy e chegando ao próprio Alencar - que funcionou não como avaliação qualitativa de uma obra literária, mas como uma construtor das bases modeladoras de uma literatura nacional. Em outras palavras, somente após a construção da estrutura de como deveria proceder a literatura brasileira é que a mesma funcionaria como representante da nacionalidade brasileira, como determinava o pensamento romântico. Após isso, o Brasil constituiria finalmente uma nação culturalmente independente com uma identidade própria a parte da antiga metrópole portuguesa.

\section{Parte V}

Mesmo depois de ter realizado literariamente os paradigmas que sugeriu em suas críticas ao livro de Magalhães, Alencar no posfácio de Iracema (1865), revisa algumas questões indicadas nas cartas. Em um determinado trecho, ele comenta o seguinte: "commetti a impudencia quando escrevi algumas cartas sobre A Confederação dos Tamoios dizer: 'as tradicções dos indigenas dão materia para um grande poema que talvez um dia alguem apresente sem ruido nem apparato, como modesto fructo de suas vigílias'”. Ele explica que passaram a supor que ele se referia a si mesmo e acreditaram também que ele já tinha um poema pronto. Contudo, apesar da tentativa de elaborar uma obra poética, iniciada "com tal vigor que levei quasi de um folego ao quarto canto", contudo, passado cinco meses, esse fôlego desapareceu (1865, p.193).

Alencar comenta que apenas o instinto o impelia a fazer crônicas e memórias indígenas, porque, como ele diz, "não tinha eu então estudos bastante para apreciar devidamente a nacionalidade de uma literatura" (1865: 194). Talvez o receio estivesse 
baseado em duas temeridades: a de que algum outro leitor, fizesse o mesmo com o seu texto o que ele havia cometido com o de Magalhães; e a de escrever algo tão complexo que fosse apenas compreendido por alguns poucos. Percebemos algum indicativo dessas questões no trecho seguinte, ao dizer que:

Ora escrever um poema que devia alongar-se para correr o risco de não ser entendido, e quando entendido não apreciado, era para desanimar o mais robusto talento, quanto mais a minha mediocridade. Que fazer? Encher o livro de griphos que o tornarião mais confuso e de notas que ninguem lê? Publicar a obra parcialmente para que os entendidos proferissem o veredicto litterario? Dar leitura della á um circulo escolhido, que emitisse juiso illustrado? (1865, p.198).

Alencar comenta que repeliu todas essas alternativas, a primeira por "afeiar" o livro; a segunda por fragmentá-lo em pedaços; e a terceira porque não seria proveitoso ter uma cerimônia benevolente de críticos. Por fim, ele decidiu que o "melhor e mais acertado foi desviar o espirito dessa obra e dar-lhe novos rumos" (1865, p.198). Sobre esses novos rumos, comenta o autor:

Em um desses volveres do espirito á obra começada, lembrou-me da experiencia in anima prosaica. $\mathrm{O}$ verso pela sua dignidade e nobresa não comporta certa flexibilidade de expressão que entretanto não vae mal á prosa a mais elevada. A elasticidade da phrase permittiria então se empregassem com mais claressa as imagens indigenas, de modo a não passarem desapercebidas. Por outro lado conhecer-se-hia o effeito que havia de ter o verso pelo effeito que tivesse a prosa $(1865$, p.199).

Na polêmica em torno do livro A Confederação dos Tamoios, como comenta Heron de Alencar ao analisar o estilo de escrita do escritor de Senhora, podemos perceber que desde esse momento, o jovem Alencar, então com 26 anos, já demonstra preocupação com o estilo da linguagem brasileira (ALENCAR, 1999, p. 265). Tal fato aparece quase dez anos depois, no ponto máximo do seu amadurecimento como escritor, permitindo a ele dizer que em Iracema:

Verá realisadas nelles as minhas idéas á respeito da litteratura nacional; e achará ahi poesia inteiramente brasileira, haurida na lingua dos selvagens. A ethmologia dos nomes das diversas localidades, e certos modos de dizer tirados da composição das palavras, são de cunho original (ALENCAR, 1865, p.200).

Nesse período, o sistema literário brasileiro se estabelece, Alencar encontrou na narrativa em prosa a maneira de dotar o Brasil, consolidando a sua ideia de nação, de uma identidade nacional. 
Ressaltamos que, além da crítica proferida por Alencar, houve também manifestações às propostas de Magalhães em São Paulo, pois Castello comenta que os grupos paulistas também estavam preocupados com as mudanças da literatura (1999: 209). Todavia, como expõe o autor, no Rio de Janeiro, "Alencar é o primeiro a discutir o significado nacional da obra de Magalhães, ao apreciar o poema A Confederação dos Tamoios, em 1856" (1999, p. 210). Segundo ele, apesar das polêmicas e críticas que sofreu de Alencar, Magalhães ainda continuou insistindo no seu erro:

A “Advertência” à reedição de 1864 de A Confederação dos Tamoios (a primeira edição data de 1856) é mais um passo retardado de Gonçalves de Magalhaes. Ele continuava fiel às primeiras posições, sem querer reconhecer as transformações subseqüentes. Preocupava-se ainda com problemas já superados do verso em correlação com a linguagem romântica. E a explicação que nos dá, persistentemente tardia, não diferia da posição retrógrada que, por volta de 1856 , haviam reclamado para o poema dele o uso da oitava rima (CASTELLO, 1999, p. 211).

Apesar disso, ainda tem de se levar em conta a posição de reformador que Magalhães merece receber (CASTELLO, 1999, p.211). Para Coutinho, na polêmica em torno da A Confederação dos Tamoios, Alencar "representou o pensamento mais avançado, como o polarizador dos anseios e esforços do espírito nacional pela posse de uma consciência técnica no tratamento e na compreensão do fenômeno literário. É um momento crucial, portanto, da evolução da crítica literária brasileira" (COUTINHO, 1968, p.174). Ele não abraçou os dogmas do Romantismo europeu, pelo contrário, Alencar sempre procurou abrasileirar esse padrão literário e, ainda conforme Coutinho, Machado de Assis, em sua natural ironia, apontou o dedo para os novos escritores que, negando aqueles preceitos, abraçaram as cegamente as novas modas europeias. Segundo o estudioso:

Foi Machado de Assis quem o afirmou: "Gente que mamou leite romântico, pode meter o dente no rosbife naturalista; mas em lhe cheirando a teta gótica e oriental, deixa o melhor pedaço de carne para correr à bebida da infância"12 Aí está, nessa nota de desengano, a pintura perfeita do estado de espírito que impregnou os escritores brasileiros na segunda metade do século XIX, e que é típico do acordar da literatura brasileira (COUTINHO, 1968, p.177).

Concordamos com a afirmação de Coutinho, de que a partir do Romantismo a literatura que se produziu no Brasil não poderia mais ser considerada como "um simples ramo da portuguêsa"13, apesar de ambas se expressarem no mesmo idioma. Com o Romantismo, ficou completo o processo da constituição de uma nova literatura, a partir da qual "a literatura brasileira encontrara o momento de sua definitiva afirmação" (1968, 
p.178). Entretanto, e foi isso que procuramos demonstrar com esse artigo, esse tipo de completude não ocorreu dentro da produção literária, mas foi alcançada a partir da construção crítica de como essa literatura deveria se expressar. José de Alencar foi seu ponto alto, tanto nessa crítica de como a literatura deveria ser, como no que essa mesma acabou sendo através de sua pena romântica.

\section{Conclusão}

Para os historiadores da literatura brasileira, foi a partir da publicação da revista Nitheroy, que se inaugurou o período romântico no Brasil desencadeando os primeiros movimentos nacionalista em prol de dotar essa nascente nação com uma identidade original - que a diferenciasse da cultura de sua antiga metrópole portuguesa -, através da constituição de uma literatura nacional. Esse movimento que fundia os campos da literatura e política, seguindo os moldes do proporcionados pelo Romantismo europeu, objetivou criar a necessária originalidade brasileira seguindo por padrão as sugestões temáticas - no caso o índio - indicadas pelos literatos do Velho Mundo. Entretanto, como mostramos, para que essa literatura filha legítima das novas terras americanas seguisse os seus desígnios originais, foi fundamental que a crítica literária - não funcionando como uma avaliação do que se produziu - trabalhasse como uma projeção da estrutura que essa literatura deveria se guiar. Vemos esses movimento desde os literatos daquela revista até o posicionamento crítico de Alencar, estabelecendo assim uma espécie de ciclo formulador da cultura nacional. Com isso, foi possível aos literatos brasileiros durante o Brasil Império, chamarem para si essa tarefa de formulação da nacionalidade. Mas o grande responsável por dar um passo adiante na constituição de uma literatura e identidade brasileira foi a figura de José de Alencar, considerado como "o patriarca da literatura brasileira", símbolo dessa verdadeira revolução literária, então realizada, cuja responsabilidade está em ter elevado a literatura nacional em seus moldes definitivos.

\section{Notas}

\footnotetext{
${ }^{1}$ Benedict Anderson com sua obra Comunidades Imaginadas (2008) é uma das poucas exceções a esse tipo de informação, pois nessa obra ele aborda o caso americano como motor do surgimento das nacionalidades.

${ }^{2}$ Existe uma longa bibliografia que cita o continente europeu como desencadeador desse movimento
} 
(BAUER, 2000; BREUILLY, 2000; CHABOD, 1997; KOHN, 1966; SMITH, 1996). A única exceção para esse preceito é o anteriormente citado Benedict Anderson.

3 Ciro Flamarion Cardoso destaca que, mesmo antes da declaração oficial de independência, o Brasil estava a beira de deixar de ser uma colônia. Esse sentido de uma quase independência política havia sido gerada a partir de diversas cirscunstânticas, como: a vinda da corte portuguesa em 1808; a extinção dos monopólios comerciais com a metrópole e a abertura dos portos para a Inglaterra, em 1810; outras mudanças significativas foram, por exemplo, a formação de um corpo estatal do império português no Rio de Janeiro; a "liberdade" intelectual na colônia; o fim da proibição de fabricas no Brasil; e também o surgimento de tipografias até então proibidas. Com a instalação da burocracia portuguesa no Rio de Janeiro, aumentou ainda mais a sua importância, além de gerar um grande aumento demográfico superando Salvador, que era "até então a maior cidade brasileira" (CARDOSO, 1996, p.106).

${ }^{4}$ Antonio Candido comenta que a partir da estabilização de sociedades mais organizadas no território da América portuguesa - por exemplo, como Minas, Bahia, Rio de Janeiro e São Paulo -, a partir da segunda metade do século XVIII, intensificada pela pelo período pombalino em Portugal, teve início um movimento nativista nessa região (2010, p.117-119). Entretanto, temos que levar em consideração que esse movimento nativista mencionado por Candido é completamente diferente do movimento nacionalista do século XIX, pois conforme Elie Kendourie o nacionalismo "pretende suministrar un criterio para determinar la unidad de población adecuada para disponer de un gobierno exclusivamente propio, para el ejercicio legítimo del poder en el Estado y para la organización justa de la Sociedad Internacional" (1988, p.1). Aquele movimento mencionado por Candido é apenas uma pretensão de reconhecimento, por parte da coroa, dos indivíduos de uma região dentro do Império Português. Um tipo de lógica anterior às formações das abstrações nacionais. É coerente para os românticos do período pós-independência olhar para esses nativistas como seus antepassados, em razão da necessidade de se criar uma tradição para a nação que se pretendia construir. No entanto, é anacrônico para um estudioso da formação da nação brasileira inferir àquele movimento nativista do século XVIII um princípio de nacionalidade.

${ }^{5}$ Cito como autores básicos do estudo da literatura brasileira Antonio Candido (2000), José Aderaldo Castello (1999) e Alfredo Bosi (1970).

${ }^{6}$ O secretário perpétuo do IHGB propôs, em 1840, um concurso para eleger um plano de como deveria ser escrita a história antiga e moderna do Brasil. Contudo, o prêmio somente foi atribuído pela comissão encarregada de analisar o concurso em 1847. A antecipação do texto, antes do parecer final, foi um descuido da redação revista (TEMISTOCLES, 2003: 174-175).

${ }^{7}$ Segundo Manoel Luis Salgado Guimarães o Instituto Histórico e Geográfico Brasileiro, fundado em 1838, tinha por objetivo pensar e escrever a história nacional. Ele desempenhou um importante papel ao reunir as elites políticas e intelectuais em torno da constituição da nacionalidade brasileira (GUIMARÃES, 1988).

${ }^{8}$ Esse texto faz parte do livro Resumo da História Literária de Portugal. O literato francês, juntamente com o português Almeida Garrett são concebidos pela historiografia literária brasileira, como os grandes incentivadores da literatura nacional (CASTELLO, 1999; BOSI, 1970).

${ }^{9}$ A obra em questão trata-se de Geschichte der Poesie und Beredsamkeit seit dem Ende des 13. Jahrhunderts (História da Poesia e da Eloqüência desde o Fim do Século XIII), Göttingen 1801-1819, 12 vols., da coleção Geschichte der Kurnst und Wissenschasften seit der Wiederherstellung derselben bis na das Ende des 18. Jahrhunderts (História das Artes e das Ciências desde a Época do seu Renascimento até o Fim do Século XVII). Nota escrita por Guilhermino Cesar (CESAR, 1978,: XV).

${ }^{10}$ Segundo nota de Guilhermino Cesar, essa obra tem 512 páginas dedicadas a Portugal, e a literatura brasileira vai da página 513 a 601 (1978: XXXII).

${ }^{11}$ Utilizaremos o livro Polêmica sobre 'A Confederação dos Tamoios' de Alencar que foi reeditado por José Aderaldo Castello, no ano de 1953, que manteve sua grafia e sintaxe original da publicação de 1873.

${ }^{12}$ Crônica de 25 de dezembro 1892. A Semana. Rio de Janeiro, Garnier, 1910, p. 49.

${ }^{13}$ É provável que Coutinho esteja dirigindo essa crítica ao comentário feito por Antonio Candido, em sua Formação da Literatura Brasileira, ao dizer que a literatura brasileira seria um ramo da portuguesa. 


\section{Referências Bibliográficas}

ACTON, Lord. Nacionalidade. In: BALAKRISHNAN, G. (Org.). Um mapa da questão nacional. Rio de Janeiro: Contraponto, 2000, pp.23-43.

ALENCAR, José de. A polêmica sobre “A Confederação dos Tamoios". José Aderaldo Castello (org.). São Paulo: Faculdade de Filosofia, Ciências e Letras / USP, 1953.

ALENCAR, José. Carta ao Dr. Jaguaribe. In: Iracema: lenda do ceará. Rio de Janeiro: Typ. de Viana \& Filhos, 1865. (acessado em 10/02/2016). (Exemplar pertente a Biblioteca Brasiliana e Guita José Mindlin. Disponível em: http://www.brasiliana.usp.br/handle/1918/00178300

ALENCAR, José. Iracema: lenda do Ceará. Rio de Janeiro: José Olympio, 1957.

ALENCAR, José. O Guarani: romance brasileiro. Rio de Janeiro: José Olympio, 1957.

ALENCAR, Heron de. "José de Alencar e a Ficção Romântica". In: A Literatura no Brasil. (dir. Afrânio Coutinho, co-dir. Eduardo Coutinho). 5ª ed. rev. E atual. São Paulo: Global, 1999.

ANDERSON, Benedict. Comunidades imaginadas: reflexões sobre a origem e a difusão do nacionalismo. [Trad. Denise Nottman]. São Paulo: Companhia das Letras, 2008.

BAUER, Otto. A Nação. In: Um Mapa da Questão Nacional. Gopal Balakrishnan (org.). Rio de Janeiro: Contraponto, 2000. p.45-84.

BREUILLY, John. Abordagens do nacionalismo. In: Um mapa da questão nacional. Glopal Balakrishnan (org.). Rio de Janeiro, 2000.

BOSI, Alfredo. História Concisa da Literatura Brasileira. São Paulo: Editora Cultrix, 1970.

BOUTERWEK, Friedrich. História da poesia e eloquência portuguesa. In: Guilhermino Cesar. Historiadores e críticos do romantismo: a contribuição européia, crítica e história literária. Rio de Janeiro: Livros Técnicos e Científicos; São Paulo: Editora da universidade de São Paulo, 1978. [1805]

CANDIDO, Antonio. Formação da literatura brasileira: momentos decisivos. 6 ed. Belo Horizonte: Editora Itatiaia, 2000.

CANDIDO, Antonio. Formação de literatura brasileira: momentos decisivos. Vol. II. 5. ed. da Universidade de São Paulo, 1975.

CANDIDO, Antonio. Letras e ideias no período colonial. In: Literatura e Sociedade: estudos de Teoria e História Literária. 11 ${ }^{\mathrm{a}}$ ed. Rio de Janeiro: Ouro Sobre Azul, 2010, p.117-148.

CARDOSO, Ciro Flamarion. A crise do colonialismo luso na América portuguesa 1750/1850. In: LINHARES, Maria Yeda (org.). História geral do Brasil. 6. ed.atual. Rio de Janeiro : Campus, c1996.

CASTELLO, Aderaldo. José. A Literatura Brasileira: Origens e Unidade (1500-1960). São Paulo: Editora da USP, 1999. 
CESAR, Guilhermino. Historiadores e críticos do romantismo - 1: a contribuição europeia, crítica e história literária. Rio de Janeiro: Livros Técnicos e Científicos; São Paulo: Editora da USP, 1978.

CESAR, Temístocles. Como deveria ser escrita a história do Brasil no século XIX. Ensaio de história intelectual. In: Sandra Jatahy Pesavento (org.) et al. História Cultural: experiências de pesquisa. Porto Alegre: Editora da UFRGS, 2003.

CHABOD, Federico. La Idea de Nación. Mexico: Fondo de Cultura Económica, 1997.

COUTINHO, Afrânio. Introdução à Literatura no Brasil. $4^{\mathrm{a}}$ ed. Rio de Janeiro: Livraria São José, 1968.

DENIS, Ferdinand. Resumo da história literária do Brasil. In: Guilhermino Cesar. Historiadores e críticos do romantismo: a contribuição européia, crítica e história literária. Rio de Janeiro: Livros Técnicos e Científicos; São Paulo: Editora da universidade de São Paulo, 1978. [1826]

GARRETT, João Batista Leitão de Almeida. Bosquejo da história da poesia e língua portuguesa. In: ZILBERMAN, Regina; MOREIRA, Maria Eunice. O berço do cânone. Porto Alegre: Mercado Aberto, 1998. [1826]

GUIMARÃES, Manoel Luis Salgado. Nação e Civilização nos Trópicos: O Instituto Histórico e Geográfico Brasileiro e o Projeto de uma História Nacional. Revista Estudos Históricos. Rio de Janeiro, n. 1, 1988, p. 5-37. http://bibliotecadigital.fgv.br/ojs/index.php/reh/article/view/1935/1074 (acessado em 10/02/2016).

HOBSBAWM, Eric. Nações e nacionalismos desde 1780: programa, mito e realidade. [Trad. Maria Celia Paoli, Anna Maria Quirino]. Rio de Janeiro: Paz e Terra, 1990.

KEDOURIE, Elie. Nacionalismo. Madrid: Centro de Estudios Contitucionales, 1988.

KOHN, Hans. El nacionalismo: su significado y su historia. Buenos Aires: Paidós, 1966.

MAGALHÃES, Domingos José Gonçalves de. Ensaio sobre a história da literatura do Brasil. Caderno do Centro de Pesquisas Literárias da PUCRS, Porto Alegre, v. 5, n. 2, ago. 1999.

PALTI, Elias. La nación como problema: Los historiadores y la "cuestión nacional". Buenos Aires: Fondo de Cultura Económica, 2006.

PAMPLONA, Marco A.; DOYLE, Don H. Nacionalismo no Novo Mundo: a Formação de Estados Nação no Século XIX. São Paulo: Record, 2008.

RENAN, Ernest. Que es una nacion? Buenos Aires: Hydra, 2000.

RICUPERO, Bernardo. O romantismo e a idéia de nação no Brasil (1830-1870). São Paulo: Martins Fontes, 2004.

SMITH, Anthony D. Historia nacional e voluntad popular: el legado de Ernest Renan. In: RENAN, Ernest. Que es una nacion? Buenos Aires: Hydra, 2000, p. 9-27.

SMITH, Anthony D. Identidade Nacional. Lisboa: Gradiva, 1997. 